Resumo

Sabemos que os primeiros anos de vida da criança são impor tantes para o desenvolvimento psiquico; por esse motivo, quando se trata de crianças muito pequenas e que freqüentam creches, faz-se necessário pensar sobre a relação que se estabelece entre os profissionais da Educação Infantil e os bebês de Berçário I. Este trabalho parte da idéia de que esses profissionais ocupam um lugar na história psíquica dessas crianças. Para isso, esta pesquisa traz o olhar da psicanálise a fim de refletir sobre as possibilidades constitutivas das crianças no espaço das Escolas de Educação Infantil.

Descritores: educação; constituição subjetiva; escola de educação infantil; psicanálise

\section{A EDUCAÇÃO INFANTIL ESCOLAR COMO ESPAÇO DE SUBJETIVAÇÃO}

\author{
Flávia Flach \\ Regina Orgler Sordi
}

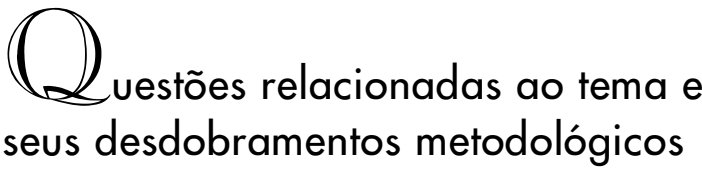

$\mathrm{O}$ atendimento à criança pequena no Brasil traz na sua história marcas de um trabalho assistencial dirigido às crianças vindas de famílias pobres e trabalhadoras, como também de um trabalho compensatório. Historicamente, o trabalho assistencial visava proporcionar à criança as condições que supunha lhe faltassem no lar. Esse foi o objetivo principal dessas instituições até poucos anos atrás, quando então a Lei de Diretrizes e Bases da Educação Nacional - LDB (1996) determinou que a Educação Infantil fosse direito de toda criança e que fizesse parte da Educação Básica. A partir dessas resoluções, o objetivo do trabalho passou a ser o de proporcionar o desenvolvimento integral da criança até os seis anos de idade. Em decorrência disso, os últi-

- Psicóloga da Prefeitura Municipal de liú, mestranda em Psicologia Social e Institucional na UFRGS, docente da

Faculdade de Psicologia da UNIJUÍ.

- Psicóloga, docente do Instituto de Psicologia da UFRGS. 
mos anos têm sido marcados por uma série de transformações, pela busca de uma identidade própria e pelo desenvolvimento de programas que visam estabelecer nas Creches a indissociabilidade entre cuidar e educar; na tentativa de tornar essas instituições cada vez mais estruturadas e reconhecidas como espaços de fundamental importância para o desenvolvimento infantil.

Muitas são as pesquisas desenvolvidas, principalmente na área da Educação e da Saúde, a fim de pensar a respeito das Creches ou Escolas de Educação Infantil, que vêm fazendo parte cada vez mais cedo da realidade da maioria das crianças e de suas famílias. Na área da Psicologia, encontramos pesquisas voltadas a questionar o caráter nocivo dessas instituições. Os trabalhos de Ferreira e Amorin (1994), Kude (1996), Pires e Mejias (1998), Eltink (1999), Pacheco e Dupret (2004) são voltados ao estudo do comportamento, à aplicação de testes e instrumentos de avaliação. Percebemos, no entanto, menos incidência de pesquisas dedicadas à questão subjetiva da criança, pois normalmente o foco dos trabalhos encontrados está no cuidado - na medida em que está ligado ao corpo e é entendido como atendimento às necessidades do corpo como organismo - e na educação, voltada a tarefas de estímulo cognitivo. Por esse motivo, este artigo traz a contribuição da psicanálise para a leitura da relação que se estabelece entre as crianças do Berçário I e suas professoras e monitoras. O objetivo é pensarmos sobre como essa relação vem sendo constituída e que reflexos terá para o desenvolvimento da subjetividade das crianças, apresentando outro olhar sobre o desenvolvimento, o cuidado e a educação.

Esse estudo contou com a participação dos monitores e das crianças de duas turmas de Berçário I de duas Escolas Municipais Infantis de uma cidade do interior do estado do Rio Grande do Sul. Essas turmas atendem crianças da faixa etária dos quatro meses até, aproximadamente, um ano e seis meses. Durante o período de observação, estavam matriculadas na Escola A 18 crianças e, na Escola B, 16 crianças, totalizando 34 crianças. Além delas, na Escola A participaram da pesquisa duas professoras e duas monitoras; na Escola B, uma professora, que trabalhava em tempo integral, e duas monitoras, totalizando sete profissionais. As escolas escolhidas para essa pesquisa pertencem a dois bairros distintos, com realidades sócio-econômicas diferenciadas. A Escola A localiza-se num bairro construído com o objetivo de servir de modelo para a cidade, e encontra-se bastante afastada da área central. As famílias que se utilizam dessa escola vivem em condições econômicas razoáveis, poderíamos dizer que pertencem à classe média e média baixa, salvo alguns casos em que as condições sócio-econômicas são precárias. A maior parte das crianças permanece, em média, 10 horas por 
dia na escola. Já a Escola B está situada em um bairro carente da cidade, onde a grande maioria das famílias encontra dificuldades no sustento e na manutenção das necessidades básicas. Nessa escola, temos uma média de permanência das crianças de 11 horas diárias.

Durante os meses de maio a dezembro de 2005 foram realizadas várias visitas às escolas, totalizando 24 turnos de observação, numa média de 96 horas de permanência junto às duas turmas de Berçário I. Durante esse tempo, foram acompanhadas as rotinas diárias, priorizando as situações de interação entre o bebê e a professora ou monitora, como o momento das trocas de fraldas, o das alimentações, a chegada das crianças, as brincadeiras, o sono e o momento de saída. Uma vez que se trata de crianças pequenas, a observação é muito sutil: são olhares, toques, pequenos gestos que dizem do laço que se constrói nesse espaço. Entendemos que esses componentes são elementos que fazem parte de uma linguagem e, por isso, podem ser escutados, interpretados e analisados.

Os registros foram de natureza descritiva e reflexiva e fizeram parte da construção de um diário de campo. Além da observação, também utilizamos a entrevista semi-dirigida com os profissionais que atuam nessas turmas de Berçário I, a fim de escutar suas idéias a respeito das crianças, de seu trabalho e sobre a relação que se estabelece entre elas.

\section{O início}

A palavra "creche" significa manjedoura, local onde se abrigam bebês necessitados. Sua denominação diz de sua função assistencial de recolhimento, abrigo, guarda de crianças, em sua maioria, vindas de famílias de menor poder aquisitivo. Segundo estudos históricos, as creches surgiram, no Brasil, no início do século XX, acompanhando o desenvolvimento do capitalismo. Por muito tempo, elas tinham a função de combater a pobreza e a mortalidade infantil.

Durante os séculos XVII e XVIII, a infância era marcada pela exposição, pelo abandono dos filhos pelos pais: por terem nascido de relações extra-conjugais, muitas entre os senhores e as suas escravas, ou por serem filhos de mães solteiras e prostitutas. Para atender essas crianças foram criadas as "Casas da Roda", ou "Casa dos Expostos", cujo objetivo era cuidar das crianças abandonadas para que não morressem. Essas casas permaneceram em funcionamento no Brasil de 1726 a 1950. A criança, ao ser abandonada, era destinada a uma criadeira, que se responsabilizava, em troca de pa-

82 Estilos da Clínica, 2007, Vol. XII, nº 22, 80-99 
gamento, pela criação até aproximadamente oito anos, quando a criança era devolvida à Casa. Nesse momento, elas eram encaminhadas a famílias como aprendizes; alguns meninos iam para as Companhias de Aprendizes Marinheiros ou do Arsenal de Guerra, já algumas meninas permaneciam nas Casas ajudando a cuidar das menores.

No século XIX, alarmados com $\mathrm{o}$ alto índice de mortalidade das crianças expostas, os higienistas pediram a extinção dessas instituições. Com relação às famílias, o discurso médico-higienista teve forte repercussão, o papel de mulher-mãe (amamentação, cuidado e educação) foi alvo de intensa campanha, combatendo, dessa forma, o trabalho das criadeiras ou amas-de-leite. No discurso médico, a mulher-mãe deveria moldar-se à imagem de uma enfermeira e, em cumplicidade com ele, lutar contra a mortalidade infantil, provocada, na maioria das vezes, pela promiscuidade, pela ignorância e por práticas inadequadas de atendimento à criança.

Em substituição às Casas da Roda fundou-se, em 1899, o Instituto de Proteção e Assistência à Infância do Rio de Janeiro e a creche da Companhia de Tecidos Corcovado, também no Rio de Janeiro, primeira creche para filhos de operários. Até início do século XX, as creches tinham como objetivo abrigar os filhos das mães solteiras, das viúvas, das abandonadas pelos maridos, ou ainda, em alguns casos, daquelas que por sua extrema pobreza tinham que trabalhar para ajudar no orçamento doméstico.

Em decorrência de uma questão econômica, da constituição da socie- dade capitalista, da urbanização e da organização do trabalho industrial, na metade do século XIX aumentou a participação da mulher no mercado de trabalho. No início do século XX, surgiram movimentos de reivindicação da classe operária, e uma das exigências era a construção de creches para seus filhos. Foi somente em 1932, com o primeiro instrumento jurídico regulamentando o trabalho feminino, que foi determinada a obrigatoriedade do oferecimento de creches nas indústrias onde trabalhassem pelo menos 30 mulheres maiores de 16 anos. Mas foi somente em 1943 que o acesso à creche foi tendo avanços.

Durante as décadas de 30 a 50, eram poucas as creches fora das indústrias; as que existiam tinham caráter filantrópico, sustentadas por doações de famílias de melhor poder aquisitivo e pelo governo. Por volta de 1950, o Ministério do Trabalho passou a desaconselhar a instalação de creches nas empresas, considerando o local inadequado e o investimento muito alto, apontando também para a falta de profissionais habilitados para o trabalho. Orientou-se a confiar a organizações assistenciais a implantação das creches. A creche sai então da alçada da Previdência, passando para a da Assistência.

$\mathrm{Na}$ década de 60, com a entrada da corrente pedagógica baseada nas teorias de privação cultural, a creche passou a ser vista como local privilegiado, para compensar deficiências bio-psico-culturais apresentadas no desenvolvimento da criança. Partiuse da hipótese de que as classes economicamente desfavorecidas estariam 
em situação de privação cultural. As dificuldades das crianças eram vistas como conseqüência da inadequação da família, principalmente da mãe, que não oferecia os estímulos necessários ao desenvolvimento do filho.

A partir do final da década de 70 , a educação das crianças de zero a seis anos adquiriu um novo estatuto no campo das políticas e das teorias educacionais. O Movimento de Luta por Creches tomou grandes proporções, a creche passou a ganhar a aceitação por parte do Estado com função de guarda e assistência à criança pobre, tornando-se direito de todo trabalhador.

Nos últimos anos, o atendimento à criança tem passado por modificações que aconteceram, principalmente, em virtude das mudanças na legislação. A partir da Constituição Federal Brasileira de 1988 é dever do Estado a garantia do atendimento em creche e pré-escola para a criança de zero a seis anos; e isso é reforçado pela Lei de Diretrizes e Bases da Educação Nacional - LDB (1996), que estabelece a Educação Infantil como primeira etapa da Educação Básica. A finalidade da Educação Infantil é o desenvolvimento integral da criança, em seus aspectos físico, psicológico, intelectual e social, dividindo o atendimento em creche para crianças de zero a três anos e em pré-escola para crianças de quatro a seis anos. Essa lei também determina que em um período de três anos todas as creches deveriam ser inseridas em seu respectivo sistema de ensino.

Essa situação volta a se modificar a partir da lei n. 11.274 de 6 de fevereiro de 2006, que altera a reda- 
ção dos artigos 29, 30, 32 e 87 da LDB de 1996, dispondo sobre a duração de nove anos para o ensino fundamental, com matrícula obrigatória a partir dos seis anos de idade. Os Municípios, Estados e Distrito Federal têm até o ano de 2010 para a implementação da obrigatoriedade; com isso, a pré-escola passa a atender crianças de 4 a 5 anos e não mais de 4 a 6 anos.

As alterações ocorridas nos últimos anos na legislação posicionam a criança como sujeito de direitos, ficando sua educação assegurada desde o nascimento. O Estatuto da Criança e do Adolescente - ECA (1990) destaca a condição de cidadania da criança, postulando que ela deve ser respeitada como ser em desenvolvimento, com necessidades e características específicas, além de ser detentora de uma série de direitos. Desse modo, a criação do filho pequeno sai do espaço doméstico e da exclusiva tutela familiar, sem que esta seja considerada ineficiente, inapta, ou portadora de alguma patologia social.

A oferta de instituições de Educação Infantil fica, a partir de então, a cargo dos Municípios. Por muito tempo, o profissional requerido para o trabalho nas creches vinha da área da saúde e da assistência, já que os conhecimentos necessários à função estavam ligados à saúde, à higiene e à puericultura. Com a passagem da creche da Assistência Social para a Educação, o quadro profissional modifica-se, há a entrada dos professores e a permanência dos monitores, que eram os responsáveis pelos cuidados das crianças desde o tempo da Assistência Social.

\section{Educação e cuidado}

Educação e cuidado são expressões quotidianamente usadas no trabalho com crianças pequenas, por isso não podemos pensar em Educação Infantil sem nos referirmos a esses dois termos, ou sem que entendamos o que significam.

"Cuidado" vem de cura (em latim cura, curare) e era utilizada nas relações de amor e de amizade, para expressar desvelo e preocupação. A palavra tem sido empregada de diferentes formas, nas diferentes áreas do conhecimento e campos profissionais. O termo assume também uma conotação de atenção, preocupação, proteção ou, ainda, de compromisso. Pelos diferentes significados, essa palavra acaba transitando pelos espaços públicos e privados, da família ao espaço profissional.

Podemos afirmar que o cuidado com bebês e crianças pequenas tem especificidades na história das relações entre os adultos e as crianças. É no século XIX que a criança ganha um estatuto 
diferente do adulto, um papel central na família e no social, tanto que, entre o final do século XIX e início do século XX, várias áreas do conhecimento, entre elas a Pediatria, a Psicologia e a Pedagogia, dedicaram-se a conhecer a criança, tornando o cuidado cada vez mais especializado.

Pensar sobre o cuidado nas escolas implica nos remetermos a dois momentos importantes. Um deles é a passagem do século XIX para o XX, quando o corpo docente, na maioria dos países ocidentais, passa a ser composto basicamente por mulheres. $\mathrm{O}$ outro acontece após a Segunda Guerra Mundial, quando o cuidado materno adquire um lugar de destaque em algumas teorias psicológicas. Durante esse período, a maternagem ganha importância destacada entre as teorias que tratam do vínculo materno e a mãe passa a ser peça fundamental no desenvolvimento dos filhos. Nesse sentido, cuidar significa amar. Associa-se o trabalho docente a características femininas, um trabalho baseado no amor e não no controle, mais próximo do materno. O cuidado desenvolvido na creche é visto então, nessa época, como substituto da mãe, ou seja, tem como finalidade suprir a falta desta. Quando se trata de "cuidado", encontramos em muitos autores a referência ao trabalho da mulher e, especialmente, ao trabalho em educação. A vida da mulher é marcada pelo cuidado aos filhos, ao marido, à mãe e muitas vezes essas atividades estenderam-se a projetos assistenciais em hospitais, creches, asilos, entre outros.

Pensar acerca do cuidado presente nas Escolas de Educação Infantil hoje implica reportar-se ao Referencial Curricular Nacional para a Educação Infantil (1998), que defende o desenvolvimento integral da criança, aliando educação e cuidado. Embora se defenda a idéia de um trabalho que associe essas duas práticas, no fazer diário das escolas pesquisadas isso não acontece. Segundo as professoras e monitoras que fizeram parte dessa pesquisa, cuidado refere-se ao atendimento das necessidades mais urgentes como alimentação, higiene e sono.

Com relação à educação, percebemos que há uma grande desconsideração a respeito de sua importância no trabalho com crianças pequenas. Zabalza (1998) sublinha que a educação só acontece com crianças acima dos três anos. Isso quer dizer que, com as crianças em idade de creche, de zero a três anos, o trabalho seria voltado às práticas de cuidado e para as crianças em idade de pré-escola, de quatro a seis anos, aconteceria o trabalho pedagógico. No entanto, existem posições diferentes quanto ao que seria uma atividade educativa na creche. Para alguns, ela se desenvolve num ambiente formal, na sala de aula. Para Oliveira (1992), o desenvolvimento infantil obedece a uma seqüência biologicamente prédefinida, cabendo à educadora criar condições para essa maturação; o que seria possível, por exemplo, por meio de atividades planejadas, buscando um direcionamento da estimulação. Nesse caso, a rotina seria extremamente importante para a estabilidade da criança, não podendo haver momentos de ociosidade. Segundo essa autora, com crianças de até 12 a 18 
meses, a rotina é organizada em função dos cuidados físicos, atendimento às necessidades básicas, a educação ficaria a cargo da apresentação de objetos como móbiles e caixas.

Para alguns autores como Rizzo (1991), o ambiente da creche deve ser pensado nos seus mínimos detalhes, seu mobiliário, seu piso, entre outros. Chama a atenção o fato de que o cuidado com os espaços tem destaque; no entanto, em nenhum momento há referência ao vínculo entre o profissional e a criança. Para a escolha dos brinquedos e para a organização das salas, não se leva em conta a criança e sim a higiene e a praticidade. O corpo não é manipulado como um corpo desejante, mas como um pedaço de carne que deve ser cuidado e estimulado para se desenvolver de forma sadia. Pensando que a educação vai além da construção e do desenvolvimento de habilidades; e também que o cuidado assume uma importância muito maior do que o simples atendimento às necessidades básicas, reportamo-nos à teoria psicanalítica, que poderá trazer-nos um novo olhar sobre essa questão.

\section{Contribuições da psicanálise à educação infantil}

Para Lacan (2005), a organização subjetiva da criança não acontece de forma natural, não é da ordem do biológico, é construída. O biológico não é objeto de estudo da psicanálise, mas sim o corpo, na medida em que se encontra inscrito no simbólico. O ritmo do desenvolvimento é marcado pelo desejo do Outro, que inscreve o sujeito numa ordem filiatória. O bebê humano ao nascer encontra-se numa situação de dependência, desprovido de todos os atributos necessários para manter sua sobrevivência; diante disso, sua reação é motora: o choro, o esperneio, o grito, aparecem como tentativas de alívio. Esse desamparo inicial deixa a criança numa condição de dependência frente a outro que venha alimentá-la, cuidar de sua higiene, falar com ela conferir-lhe traços identificatórios. É então o Outro primordial o responsável pelas primeiras marcas fundantes de sua constituição. O bebê está numa posição de ser falado, tocado, olhado por esse Outro que, em seus cuidados, vai tecendo a articulação entre as manifestações espontâneas do bebê e a significação simbólica que ele lhes atribui. Podemos dizer, então, que a pessoa que exerce a função materna toma essas manifestações como demandas a ela dirigidas, assumindo o estatuto de chamado, acrescentando às necessidades do bebê uma significação, dando a elas um sentido.

Esse saber produzido pelo $\mathrm{Ou}$ tro sobre o bebê é, para Lacan (1999), da ordem da dúvida. É importante que o cuidador não se sinta na obrigação de responder a tudo; que as demandas, tanto dele como do bebê, estejam submetidas à Lei; que possa existir uma alternância entre presença-ausência. Com essa alternância dos cuidados, os ritmos vão sendo organizados, inscrevendo o bebê no circuito de satisfação e insatisfação. Segundo J. Jerusalinsky (2002), é importante que se sustentem os quatro eixos que referendam a constituição da subjetividade, e que são: suposição de 
um sujeito, estabelecimento de demanda, alternância presençaausência e alteridade. Falaremos brevemente sobre cada um desses eixos.

Encontramos a suposição de um sujeito quando a mãe ou cuidador, na sua relação com o bebê, permite-se olhar e escutar para além do que está ali. Ouvir, diante do choro, um pedido, e a ele dar uma resposta, certificando-se de que ela foi acertada, "será que era mesmo isso que ele queria?" No momento da dúvida, há a suposição de um sujeito no bebê, uma suposição de desejos nele, para além dos seus. Com relação a isso, podemos dizer que nas Escolas de Educação Infantil pesquisadas há uma antecipação de tudo; antecipam-se a fome, a sede, o sono, e isso acaba por obturar a brecha por onde o sujeito poderia aparecer.

O estabelecimento de demanda diz do reconhecimento por parte do cuidador de que as manifestações da criança são pedidos a ele dirigidos; pedidos que necessitam de tradução, de resposta. No entanto, esse cuidador não precisa ver-se na obrigação de responder a tudo; é importante que haja momentos de espera e isso está relacionado à alternância presença-ausência. Que a relação entre o cuidador e a criança não seja marcada apenas de presença ou de ausência, que haja uma alternância, embora tenhamos encontrado, principalmente na Escola B, uma prevalência da ausência.

Por último, temos a alteridade, que diz respeito à sustentação da função paterna, que faz com que a criança renuncie à mãe tornando-se um sujeito desejante. É importante entendermos que esses quatro eixos não comparecem de maneira separada durante o processo de desenvolvimento, eles se entrelaçam nos cuidados prestados pela mãe e seus substitutos.

É importante destacarmos o fato de que existe uma diferença fundamental entre o cuidado prestado pelo Outro primordial e pelo Outro cuidador em uma instituição. Entendemos o Outro primordial como aquele que vem inserir o bebê num laço de filiação, para que este venha a ocupar um lugar de objeto $a$, lugar de quem se oferece como objeto de completude, o que não acontece entre as crianças e seus cuidadores. O Outro cuidador inscreve o sujeito na cultura, no laço social; é um Outro que está atravessado pela função paterna encarnada na instituição, nas regras da escola, ordenando à criança um determinado ritmo. Tanto o Outro primordial como o Outro cuidador são importantes para a constituição psíquica da criança e produzem marcas, mas são marcas de diferentes ordens. Como diz Baptista (2003): “...é possível dissociar a Função da mãe da maternagem, pois quem cuida não necessariamente faz inscrição, (...). Assim, a maternagem poderá ser abordada sob outro prisma: os cuidados com os bebês serão realizados por um adulto, pro-

88 Estilos da Clínica, 2007, Vol. XII, n² 22, 80-99 
fissional que trabalha na creche, independentemente de sua formação, já que a maternagem faz parte do cotidiano da creche, ...” (p. 70)

Os cuidados prestados à criança vão, então, além do simples atendimento às necessidades de alimentação, higiene, saúde e movimentação. É através das práticas de cuidado que essa criança vai se constituindo subjetivamente

Segundo Crespin (2004), existem três registros pulsionais fundamentais para o desenvolvimento do bebê: a oralidade, a especularidade e a pulsão invocante.

A oralidade é marcada pelas trocas alimentares do bebê, que vão além da simples resposta às necessidades orgânicas de fome $\mathrm{e}$ sede; é uma troca de amor. $\mathrm{Na}$ alimentação, o bebê absorve o leite para a sua sobrevivência e os sinais da presença materna, seu desejo, seu olhar, sua voz, indicando satisfação.

A especularidade diz respeito ao olhar, que deve ser entendido de forma diferente da visão. A visão é o funcionamento do órgão; o olhar tem a ver com a função psíquica, é um indicador de presença, corresponde ao ser visto. $\mathrm{O}$ acesso ao especular depende do reconhecimento da imagem de si, que acontece através do estádio do espelho desenvolvido por Lacan (1998).

Para Winnicott (1975) "o que vê o bebê quando olha para o rosto da mãe? Sugiro que, normalmente, o que o bebê vê é ele mesmo. (...). Muitos bebês, contudo, têm uma longa experiência de não receber de volta o que estão dando. Eles olham e não vêem a si mesmos. Há conseqüências."(p. 154)

A pulsão invocante, que concerne à palavra e à voz, tem como seu primeiro momento o choro do nascimento; choro ouvido como apelo. A partir daí, já podemos considerar o bebê um sujeito falante; sua movimentação, seus resmungos, gritos e choros serão elementos de comunicação e deverão ser interpretados pelo Outro como demandas a ele dirigidas, para que possam ser interpretadas e respondidas; isso é muito importante para o desenvolvimento da criança. É dessa forma, através do som, da palavra, que se estabelece uma troca entre o cuidador e a criança, é através da voz que esses adultos a introduzirão no mundo simbólico.

Ligado a isso está a educação, Freud (1930/1988a) compreende-a como uma prática que tenta ajustar o homem aos interesses da civilização. O autor (1933/1988b) diz que ela produz, na criança, certa dose de desprazer, provocada pela renúncia às satisfações pulsionais imediatas, a fim de adaptar seu comportamento às normas sociais, à realidade externa. Educar é permitir o ingresso na cultura, é situar a criança com relação à lei e aos códigos que organizam o social. 
Lajonquière (2000) salienta que educar é transmitir marcas simbólicas que possibilitam ao sujeito lançarse nos caminhos do desejo. É o ato pelo qual o Outro primordial transforma o corpo do bebê em linguagem, pelo qual o adulto marca a criança com as marcas do desejo. Nesse contexto, a educação primordial pode ser entendida como o que possibilita a passagem da criança da posição de objeto para sujeito, no campo do discurso.

Para a psicanálise, a educação está ligada à lei, à função paterna, a algo que vem organizar o sujeito, introduzindo-o nos hábitos morais. $\mathrm{O}$ adulto que educa deve, então, invocar a lei a fim de ordenar o mundo à criança; diferente do que acontece com as regras, que impõem uma igualdade, um comportamento padrão que deve ser aceito e respeitado por todos, como diz Lajonquière (2000): "Enquanto a lei é a expressão da vontade geral de renunciar a alguma coisa - aquilo mesmo que a lei proíbe - , a regra, ao contrário, é o princípio constitutivo de hábitos morais. A lei proíbe e abre um leque de possíveis outros. (...) Isto é, a lei diz "não faça isso, porém faça outra coisa" enquanto que a regra formula o imperativo de fazer como todos ou, caso contrário, não fazer nada." (p. 76).

Com isso podemos dizer que, educar é então subjetivar. Diferente do que temos com relação à Pedagogia, que tem como um de seus objetivos organizar atividades cujo objetivo é desenvolver habilidades e/ou capacidades, ou seja, proporcionar o desenvolvimento da criança através de atividades de caráter estimulatório.
A Escola de Educação Infantil pode ser entendida então como um lugar de inscrição social que vai além do pedagógico, do ensinar as coisas; ela está ligada à cultura, a inserir o sujeito numa ordem, na Lei. No entanto, a escola não é o espaço inaugural de subjetivação, a família é a responsável pelas primeiras marcas, pelas inscrições de ordem filiatória que organizam o sujeito num sistema de parentesco. A entrada na escola pressupõe uma interrupção, uma separação, ao mesmo tempo em que dá continuidade à educação iniciada na família, apresentando o mundo à criança. Entendemos então que para além da família, a creche ou escola de educação infantil pode ser pensada como um espaço subjetivante e que é na relação entre os cuidadores, sejam eles professores ou monitores, que as crianças poderão se organizar subjetivamente.

Podemos então nos perguntar: será que as instituições de atendimento à criança pequena conseguem, na prática, sustentar os eixos que referendam a constituição subjetiva? Será que essas instituições realmente podem ser vistas como espaços de subjetivação?

\section{Relato das observações}

Diante das transformações que vêm ocorrendo com relação aos investimentos e ao entendimento de Educação Infantil, surgem discussões em torno do que seria prioridade no atendimento à criança pequena: se é atender as necessidades sociais ou se é investir nas práticas pedagógicas. 
Para muitos profissionais, o trabalho, hoje, continua a ser de creche, ou seja, com ênfase no cuidado assistencial; um cuidado voltado às necessidades básicas. Nesse modelo de Educação Infantil como substituta da família nas atividades de rotina é possível perceber que o aspecto educacional é visto apenas como tarefas pedagógicas, incluídas nos intervalos de uma rotina, muitas vezes rígida e voltada à alimentação e à higiene.

Com relação à organização da rotina diária das crianças, percebemos que, embora ela seja a mesma para todas as Escolas Municipais Infantis, elas acontecem de forma diferente. $\mathrm{Na}$ Escola $\mathrm{A}$, as crianças chegam aproximadamente às 8 h., elas são recebidas pela professora ou pela monitora. As que necessitam recebem uma mamadeira na chega$\mathrm{da}$, enquanto algumas deitam em um colchão outras pegam objetos para brincar. Por volta das 9h30, é servido o lanche, mas nem todas as crianças comem nesse horário. Durante o dia não há um horário estipulado para a troca de fraldas, elas acontecem conforme a necessidade de cada um. Em torno das 10 h30 o almoço é organizado, as crianças são alimentadas no chão, em cadeiras ou poltronas, não há um local específico para isso. Ao meio dia elas são encaminhadas aos berços, é a hora do sono. A maioria das crianças dorme sem a necessidade de uma atenção especial. Não há um horário estipulado para acordar; conforme a necessidade, algumas despertam mais cedo, enquanto outras permanecem dormindo. Por volta das 15 h. é servido o lanche, até que aos poucos elas vão indo embora, as últimas saem por volta de $18 \mathrm{~h}$.

O que podemos perceber, é que as profissionais não se preocupam em cumprir um horário determinado, a não ser o do almoço. Não há um horário específico para os lanches, à medida que as crianças vão pedindo ele é oferecido; o mesmo vale para o sono: as crianças não são obrigadas a dormir e acordar todas na mesma hora. Segundo as profissionais, a rotina existe, mas é flexível; existe o respeito ao tempo de cada criança.

$\mathrm{Na}$ Escola B, as crianças chegam um pouco mais cedo, por volta das 7h30. Logo que chegam vão para o trocador, onde uma das profissionais verifica suas roupas, tira os calçados e encaminha-as ao berço, onde recebem uma mamadeira de leite para que consigam dormir. Muitas resistem ao sono, levantam e ficam em pé no berço, mas são novamente deitadas - há uma grande insistência para que durmam. Independentemente do horário em que dormiram, elas são despertadas às 9 horas, pois é a hora do lanche. Quando todas elas já comeram é a hora de trocar as fraldas, e do trocador elas vão para o chão, onde há alguns brinquedos. Às 10 h30 é servido o almoço, em cadeiras apropriadas para isso. Às $12 \mathrm{~h}$ as crianças são novamente colocadas nos berços para a hora do sono, e às $15 \mathrm{~h}$ são acordadas para o lanche, trocadas e colocadas no chão com os brinquedos, até o horário da saída que acontece até as 18 h30 aproximadamente.

Nessa escola, percebemos que a organização da rotina segue um horário rígido, o que permite supor que todas sintam fome, sede e sono no 
mesmo horário. Segundo a professora, a rotina é simples e mecânica, passam todo o dia entre alimentações e trocas, não há tempo para as crianças. Em alguns momentos, foi possível perceber situações como: ao final do almoço um bebê de cinco meses, que estava sentado no carrinho, começa a demonstrar sinais de cansaço, fecha os olhos e vai caindo para os lados. Observando isso, a professora passa a mexer com a criança a fim de despertá-la, dizendo que ainda não estava na hora de dormir; se dormisse nesse horário, acordaria antes das outras crianças, atrapalhando o sono das demais. A professora vai então para o seu horário de almoço, permanecem na sala a monitora e a pesquisadora, a criança então dorme. Ao retornar, a professora observa que o bebê dormiu e cobra da monitora o fato de ter deixado isso acontecer, ela então pega a criança no colo agitando-a para que desperte, o que acontece, provocando o choro. Isso demonstra claramente que não há um respeito quanto ao ritmo e ao desejo da criança. A organização se impõe.

Nessa escola, as profissionais afirmam ter um saber sobre as crianças; saber esse construído através dos anos de experiência e do convívio diário. Para elas, a causa dos choros, dos resmungos, diz da rotina de trabalho; dependendo do horário em que eles acontecem, têm um sentido específico: fome, dor, manha, como se os desejos fossem organizados segundo o movimento dos ponteiros do relógio. Essa certeza absoluta frente ao que se passa com a criança condena-a a um aprisionamento, pois o significante não tem como ser introduzido. Não levar em conta o desejo desse pequeno ser, não supor que ali há um sujeito, pode deixá-lo numa condição de objeto de outro, um objeto que funcionaria segundo as previsões de suas cuidadoras. Com isso, podemos ver que não existe a suposição de um sujeito no bebê, de que possa haver algo além do determinado pelos profissionais. Outro exemplo disso foi uma atitude da professora no momento das alimentações; ao oferecer o alimento ela enchia bem a colher e empurrava para dentro da boca da criança e, sem esperar o tempo necessário para ela engolir, empurrava mais uma colherada, e assim sucessivamente, até que começavam as ânsias, tosses e vômitos. A professora, irritada, insistia um pouco mais e acabava desistindo, dizendo: "Se você não quer comer não te dou mais e pronto". Por vezes, empurrava mais comida, dizendo: "Tu precisa comer se não vai pro hospital e vai tomar inję̧ão".

Parecem ficar claras as dificuldades desse profissional em ver no outro alguém com desejos e necessidades diferentes dos seus, além de não respeitar o tempo da criança para que possa obter prazer com a alimentação. Esse prazer está ligado à pulsão oral e não se refere somente à sucção, à alimentação, mas à palavra. A função orgânica ligada à necessidade precisa estar articulada ao significante para 
que seja interpretada como demanda. Quanto mais a alimentação ficar marcada simplesmente pela ingestão de alimentos e a resposta ficar ligada à necessidade, mais a criança poderá se recusar a comer, como tentativa de barrar a intrusão desse cuidador, ou seja, a recusa como forma de sustentar a sua posição desejante.

Freud (1905/1988c) fala que a relação que a criança estabelece com quem a cuida é uma fonte de satisfação, a alimentação, por exemplo, vai para além da satisfação orgânica da fome. Nas manipulações do vestir, do trocar, também têm lugar as sensações provocadas pela satisfação.

Assim, quando falamos em cuidado, não estamos nos referindo à simples realização de tarefas, mas sim de um cuidado que produz marcas simbólicas, um cuidado subjetivante. É, portanto, na relação que se estabelece entre o bebê e seu cuidador que poderá haver uma facilidade ou dificuldade com relação à instalação do psiquismo, podendo até mesmo ser a causa de sintomas precoces como os refluxos, os vômitos, os distúrbios do sono, entre outros. A questão essencial que se impõe é que a maternagem precisa ser realizada, independentemente de ser o professor ou o monitor o seu responsável, pois, segundo Penot (1997), a falta do estabelecimento do laço entre a criança e seu adulto cuidador pode impedir a constituição psíquica de um sujeito.

Foi possível perceber também que na Escola B, na grande maioria das vezes, as crianças não eram escutadas, seus apelos não recebiam tradução, o grito virava puro grito, o choro, puro choro, vazio de sentido. Sem obter respostas para seus apelos, acabavam silenciando. É através da voz, da palavra, que se estabelece a troca entre o cuidador e a criança; é através dela que poderá demonstrar satisfação ou insatisfação. Somente quando suas manifestações forem vistas como um apelo dirigido a um Outro é que elas sairão do registro da necessidade, transformando-se em demanda.

Penot (1997) comenta que um dos elementos pelo qual podemos detectar sinais precoces de transtorno psíquico seria a falta de olhar entre o bebê e a sua mãe ou seu cuidador; o olhar, então, é de fundamental importância para a vida psíquica da criança. É através dele que o desejo será expresso, é por ele que o bebê se vê, por onde terá acesso aos significantes da sua história, sentindo-se amado e seguro.

Com relação a esse aspecto, encontramos diferenças nas observações realizadas na Escola A e na Escola B: na primeira, parece existir um envolvimento maior por parte dos educadores com as crianças, observamos que existem tentativas, principalmente durante as trocas e as alimentações, de um atendimento mais individualizado. Enquanto realizam essas tarefas, vão conversando, tocando e 
olhando a criança, atribuindo um sentido às suas reações. Com isso, percebemos que as crianças procuravam ativamente o olhar adulto na ocasião de uma queda, de alguma briga entre eles, de uma conquista, para que então fossem significados. Já na Escola B, não encontramos momentos de atenção exclusiva à criança nem nos dias em que havia apenas duas crianças na sala de aula. Como elas praticamente não eram atendidas, no restante do tempo, pouco procuravam o olhar dos adultos. Percebemos em algumas delas um olhar vago, para o nada, sem demanda, o que pode caracterizar sinais de desamparo psíquico.

Além disso, podemos perceber que há, nessa escola, uma incidência muito grande de faltas que são justificadas por motivo de doença: das 18 crianças matriculadas, durante os dias de observação, não se encontravam presentes mais do que oito delas, chegando, inclusive, em muitos dias, a permanecerem duas crianças na sala de aula. Será que as causas dessas faltas podem ser justificadas apenas com base no mal-estar físico? Que questões psíquicas poderiam estar implicadas?

Podemos relacionar a isso o fato de termos presenciado, em vários momentos, crianças recusando a alimentação. Um dos casos mais sérios foi o de um menino de um ano e três meses que vinha manifestando certa apatia, não reagia a agrados e desagrados, ficava deitado no berço, quieto, olhando para o nada; não buscava o olhar dos educadores. Esse comportamento não era percebido pelos adultos cuidadores, já que não havia, por parte deles, um olhar de investimento para com essa criança. Com o passar do tempo, ela começou a recusar a alimentação, aceitava apenas a mamadeira, complicando ainda mais a sua situação. Foi somente então que a professora percebeu que algo não ia bem, conversou com a mãe e exigiu que esta tomasse providências. O menino foi levado ao médico, que detectou um quadro de anemia profunda, podendo evoluir para uma leucemia, caso não fosse tratado corretamente. Por vários dias ele permaneceu em casa, sob os cuidados da mãe. Quando retornou para a escola estava organicamente melhor, mais forte, mais ativo; não houve, porém, qualquer modificação com relação ao atendimento que recebia na escola, sua apatia continuou evidente, como se ele tivesse desistido de reivindicar seus desejos, de se fazer escutar pelo Outro.

Segundo Spitz (1998), privar a criança do desprazer durante o primeiro ano de vida é tão prejudicial quanto privá-la do prazer, ou seja, tanto o prazer como o desprazer são importantes para a formação do sistema psíquico. A alternância presença-ausência corresponde à possibilidade que o adulto cuidador tem de não responder a todos os pedidos da criança, abrindo espaço para a entrada da lei, de um terceiro. Isso quer dizer que a relação entre o cuidador e a criança não pode ser marcada só de presença e nem só de ausência; um cuidador sempre presente obtura a possibilidade da falta e, com isso, a organização do desejo, não há a suposição de um sujeito, não há interrogações, só certezas. E quando um 
cuidador se coloca como pura ausência, o bebê não se manifesta, não convoca a presença materna. Diante do que observamos do trabalho das professoras e monitoras, podemos dizer que essa alternância pouco acontece, pois, como já dissemos em outros momentos, a maioria dos pedidos das crianças não são atendidos. As dificuldades no estabelecimento do jogo de presença e ausência também ficam visíveis quando a professora da Escola B ignora o tempo de resposta das crianças no momento das refeições, conforme descrevemos anteriormente, e na falta da troca de olhares e de fala.

Nos cuidados prestados à criança existe uma relação complementar entre a função materna e paterna: ao mesmo tempo em que a mãe responde ao pedido do filho dando de mamar, ela precisa supor que ali há um sujeito, percebendo quando ele está saciado, independentemente de querer continuar a oferecer o seio. Dessa forma, a função paterna age como um limitador do gozo materno, possibilitando o desenvolvimento psíquico desse pequeno ser. Nas Escolas de Educação Infantil, os professores e monitores sustentam esse lugar de lei, que diz da organização da instituição, da rotina diária e da organização social. Diante disso, podemos dizer que a Escola B parece organizar-se através da regra, da imposição de uma ordem que ignora os desejos dos sujeitos ali implicados, uma vez que nada pode sair do planejamento. Já a Escola A parece conseguir trabalhar com a lei, sustentando a organização da instituição sem perder de vista os dese- jos individuais, o que abre a possibilidade para uma rotina mais flexível.

Podemos dizer então, que a Escola B parece encontrar-se presa ao período Pós Primeira Guerra Mundial, até aproximadamente 1942 , quando nos Estados Unidos, segundo Spitz (1998), os bebês eram alimentados segundo um programa rígido, subordinado ao relógio e com uma quantidade pré-determinada de alimento, sem levar em consideração as necessidades e a satisfação das crianças, impondo-lhes um padrão alimentar. Dessa forma, podemos dizer que nesse modelo de trabalho não há possibilidade do atravessamento da função paterna, da lei, visto que o que opera é a regra, a anulação da criança como sujeito impondo a ela desejos pré-determinados por uma rotina rígida e inflexível. Mas que conseqüências isso acarretaria para o desenvolvimento psíquico das crianças?

\section{Considerações finais}

Entendemos que, em razão das modificações que aconteceram no decorrer da História, o trabalho desenvolvido junto às crianças pequenas assumiu um lugar de importância social, fonte de pesquisas e investigações. Até o presente momento, ainda são poucos os trabalhos dedicados a pensar a respeito do desenvolvimento psíquico das crianças nesse espaço; a maioria das pesquisas está voltada para a área da Educação, com a apresentação de novas propostas pedagógicas para o trabalho na Educação Infantil. Existem também alguns trabalhos na área da Psicologia 
que buscam pensar a respeito do processo de adaptação da criança nessas instituições, enquanto outras apresentam novas técnicas estimulatórias, a fim de contribuir para o desenvolvimento das crianças. Acreditamos que a psicanálise pode nos proporcionar um olhar diferenciado, que nos leva a pensar que essas instituições, além de serem espaços coletivos marcados pela educação e pelo cuidado, assumem um papel de importância para a constituição subjetiva da criança, ocupando um lugar de representantes do universo simbólico, da cultura. Mas isso vai exigir dos professores e monitores, segundo Mariotto (2003, p.46), "não apenas um olhar diferenciado sobre a criança em constituição, mas também uma abertura para fazer de sua prática uma interrogação permanente, capaz de provocar uma mudança de posição junto à criança que é atendida, cuidada e educada.".

A idéia inicial era a de que encontraríamos um espaço subjetivante nas escolas observadas, onde as relações entre as crianças e suas professoras e monitoras fosse um elemento importante para o desenvolvimento psíquico. Percebemos, porém, que o espaço encontrado, principalmente na Escola $\mathrm{B}$, parece não dar condições para a construção da subjetividade através do brincar e da fantasia, ou mesmo propor modificações na rotina estabelecida no espaço familiar, como o horário do sono e o das alimentações.

Com relação ao que observamos nas escolas pesquisadas, foram encontradas diferenças fundamentais entre a Escola A e a Escola B. $\mathrm{Na}$ primeira, encontramos um espaço de maior respeito à criança e as suas famílias, no qual os elementos que referendam a constituição subjetiva parecem conseguir se organizar. A Escola B, porém, apresentou um quadro preocupante; percebemos, durante o período de observação, que as crianças encontravam-se numa situação de pobreza simbólica, de desamparo psíquico. Isso foi demonstrado por algumas crianças nas suas ações; nos seus mínimos gestos - através do olhar vago, para o nada; nos adoecimentos constantes; nos problemas alimentares e de sono, entre outros. Há uma dificuldade clara, nessa escola, em operar com os eixos fundamentais para a constituição subjetiva, e isso pode trazer como conseqüência a possibilidade do desenvolvimento de patologias psíquicas. Sabemos, no entanto, que não podemos nos referir a patologias específicas, uma vez que elas não são decididas na infância e o desenvolvimento psíquico não acontece de maneira lógica e previsível. Segundo A. Jerusalinsky (2002), para que o sujeito nasça como ser falante, é necessário que alguém suponha nele um sujeito e lhe dê a chance de pedir e de representar o que ele não é. Caso isso não venha a acontecer, há condições de risco psíquico.

Penot (1997) fala de alguns indicadores de risco para a evolução do autismo, propondo uma intervenção precoce, no sentido de prevenir a evolução da síndrome. Sabemos que normalmente o trabalho clínico acontece a posteriori, mas, segundo a autora, seria possível uma intervenção assim que aparecessem os primeiros 
sinais de que algo não vai bem com a criança. Seria preciso, então, detectar os sinais de risco psíquico a partir dos quais pudesse ser organizado um trabalho de intervenção precoce; entendendo essa intervenção não para efeito de cura ou para erradicar os sintomas infantis, mas para poder acompanhar esse bebê quando começa a apresentar sinais de sofrimento.

Caberia a partir de agora uma investigação mais profunda, a fim de verificar os motivos pelos quais os quatro eixos que referendam o processo subjetivo não estão sendo operados, principalmente na Escola B. Para isso, é preciso fazer uma leitura da instituição e das relações que lá se estabelecem, proporcionando espaços de escuta, dando condições para a circulação do simbólico, o que teria efeito direto sobre as crianças, dando a elas a possibilidade de uma inscrição no mundo desejante. Não se trata de pensar na psicanálise como um saber que venha a dizer o que deve ser feito, mas sim de oferecer às crianças e aos adultos um espaço de escuta daquilo que está sendo feito. Abrir para a possibilidade de fala pode, então, trazer à tona as dificuldades que se produzem na relação entre as crianças e as suas cuidadoras, podendo, a partir daí, abrir para o surgimento de novos caminhos.

\footnotetext{
Abstract

CHILDREN EDUCATION IN THE NURSERY SCHOOL AS A SPACE OF SUBJECTIVATION

We know that the first years of children's lives are important for the psychic development, for this reason, considering their early age and the fact that they attend nursery schools, it is necessary to think about the relationship established between professionals of children's
} 
education and the nurseries of 1's babies. This research starts from the idea that these professionals hold a place in these children's psychic history. In order to do that, this research brings the view of psychoanalysis in order to reflect on the constitutive possibilities of children in Nursery Schools.

Index terms: education; subjective constitution; nursery schools; psychoanalysis

\section{RESUMEN}

LA EDUCACIÓN INFANTIL EN LA ESCUELA COMO ESPACIO DE SUBJETIVACIÓN

Sabemos que los primeros años de vida de un niño son importantes para el desarrollo psíquico; por ese motivo cuando se trata de niños pequeños y que ya van a la guardería, se hace urgente y necesario pensar la relación que se establece entre los profesionales de la educación infantil y parvularia y eses chicos. Este trabajo parte de la idea de que esos profesionales ocupan un lugar en la historia psíquica de esos niños, para eso esta pesquisa trae la mirada en el espacio de educación infantil.

Palabras-clave: educación; constituición subjetiva escuela de educación infantil

\section{REFERÊNCIAS BIBLIOGRÁFICAS}

Ariès, P. (1981). História social da criança e da familia (D. Flaksman, trad., 2a ed.). Rio de Janeiro: LTC Editora.

Baptista, V. F. (2003). Amar, cuidar, subjetivar - implicações educacionais na primeira infância. Estilos da Clínica: Revista sobre a Infância com Problemas, 8 (15), 58-71.

Bernardino, L. F. (2002). O Desenvolvimento, a perspectiva estrutural e a psicanálise. In L. M. F. Bernardino (Org.). O Bebê e a modernidade: abordagens teórico-práticas. (pp. 61-4). São Paulo: Casa do Psicólogo.

Carvalho, M. P. de. (1999). No coração da sala de aula: gênero e trabalho docente nas séries iniciais. São Paulo: Xamã.

Cerisara, A. B. (2002). Professoras de educação infantil: Entre o feminino e o profissional. São Paulo: Cortez.

Constituição da República Federativa do Brasil de 1988 (21 ed.). (1999). São Paulo: Saraiva.
Corazza, S. M. (2000). História da infância sem fim. Ijuí, RS: UNIJUÍ.

(2002). Infância \& educação - era uma vez-quer que conte outra vez? Petrópolis, RJ: Vozes.

Costa, J. F. (1999). Ordem médica e norma familiar (4a ed.). Rio de Janeiro: Graal.

Crespin, G. (2004). A clínica precoce: O nascimento bumano. São Paulo: Casa do Psicólogo.

(1988a). O mal-estar na civilização. In S. Freud, Edição standard brasileira das obras psicológicas completas de Sigmund Freud. (J. Salomão, trad., Vol. 21, pp. 75-174). Rio de Janeiro: Imago. (Trabalho original publicado em 1930). (1988b). Novas conferências introdutórias sobre psicanálise. In S. Freud, Edição standard brasileira das obras psicológicas completas de Sigmund Freud. (J. Salomão, Trad., Vol. 22, pp. 13-222). Rio de Janeiro: Imago. (Trabalho original publicado em 1933).

Freud, S. (1988c). Três ensaios sobre a teoria da sexualidade. In S. Freud, Edição standard brasileira das obras psicológicas completas de Sigmund Freud. (J. Salomão, trad., Vol. 7, pp. 118-230). Rio de Janeiro: Imago. (Trabalho original publicado em 1905).

Jerusalinsky, A. (2002). O nascimento do ser falante. In L. M. F. Bernardino (Org.), O bebê e a modernidade: abordagens teórico-clinicas. (pp. 51-60). São Paulo: Casa do Psicólogo.

Jerusalinsky, J. (2002). Enquanto o futuro não vem: A psicanálise na clínica interdisciplinar com bebês. Salvador, BA: Àgalma.

Júnior, M. K. (1998). Infância e educação infantil: Uma abordagem bistórica. Porto Alegre, RS: Mediação.

Lacan, J. (1998). O estádio do espelho como formador da função do eu. In J. Lacan, Escritos (V. Ribeiro, trad., pp. 96-103). Rio de Janeiro: Jorge Zahar.

Lacan, J. (1999). O seminário, livro 5: As formaçôes do inconsciente, 1957-1958 (V. Ribeiro, trad.). Rio de Janeiro: Jorge Zahar. 


\section{Dossiê}

. (2005). O seminário, livro10: Angústia, 1962-1963 (V. Ribeiro, trad.). Rio de Janeiro: Jorge Zahar.

Lajonquière, L. de. (2000). Infância e ilusão (psico) pedagógica: Escritos de psicanálise e educação ( $2 \mathrm{a}$ ed.). Rio de Janeiro: Vozes.

Lei n. 8069, de 13 de julho de 1990. (4a ed.). (1994). Estatuto da Criança e do Adolescente: São Paulo: Atlas.

Ministério da Educação e do Desporto. Secretaria de Educação Fundamental. (1998). Referencial Curricular Nacional para a Educação Infantil. Brasília, DF: MEC/SEF.

Lei n. 9.394, de 20 de dezembro de 1996. (1996, 23 de dezembro). Estabelece as Diretrizes e Bases da Educação Nacional. Diário Oficial da União, seção 1.

Oliveira, Z. M. (1992). Creches: Crianças, faz de conta \& cia. (5a ed.). Rio de Janeiro: Vozes.

Mariotto, R. M. M. (2003). Atender, cuidar e prevenir: a creche, a educação e a psicanálise. Estilos da Clínica: A Revista sobre a Infância com Problemas, 8 (15), 34-47.

Penot, M. C. L. (1997). Rumo à palavra: Três crianças autistas em psicanálise. São Paulo: Escuta.

Rizzo, G. (1991). Creche: Organização, montagem e funcionamento (3a ed.). Rio de Janeiro: Francisco Alves.

Spitz, R. A. (1998). O primeiro ano de vida (E. M. B. da Rocha, trad.). São Paulo: Martins Fontes.

Winnicott, D. W. (1975). O brincar e a realidade (J. O. A. Abreu \& V. Nobre, trad.). Rio de Janeiro: Imago.

(1988). Os bebês e suas mães (J. L. Camargo, trad.). São Paulo: Martins Fontes.

Zabalza, M. (1998). Qualidade em educação infantil. Porto Alegre, RS: Artmed.

flavia@unijui.tche.br sordi.voy@terra.com.br

Recebido em janeiro/ 2007. Aceito em maio/ 2007. 